\title{
Temporal and spatial variation in the reproductive ecology of the vent-endemic amphipod Ventiella sulfuris in the eastern Pacific
}

\author{
M. Sheader ${ }^{1, *}$, C. L. Van Dover ${ }^{2}$ \\ ${ }^{1}$ School of Ocean \& Earth Science, University of Southampton, National Oceanography Centre, European Way, \\ Southampton SO14 3ZH, UK \\ ${ }^{2}$ Biology Department, College of William \& Mary, 323 Millington Hall, Williamsburg, Virginia 23187, USA
}

\begin{abstract}
Populations of the vent-endemic amphipod Ventiella sulfuris were compared from 6 East Pacific Rise (EPR) vent sites of different ages, 3 from the northern EPR and 3 from the southern EPR. Although vent age affected amphipod abundance, with no individuals at the oldest vent, other population/reproductive parameters were found to be site dependent rather than vent age dependent. There was little within-site variation in population structure and reproductive output, probably the result of high within-site motility. However, there were significant between-site and betweenfield differences, indicating a high degree of population and reproductive variability and a moderate degree of vent fidelity. Since population structure and reproductive output varied between sites, the possibility of their use as biomarkers of vent 'condition' is discussed. The reproductive ecology of $V$. sulfuris is described for the first time and compared to that of other vent amphipod species. Unlike other species studied, reproductive output is relatively high. Adults move to the periphery of vents to reproduce and brood; after brooding, they moult again, return to feed at vent habitats (e.g. mussel and tube worm beds), and undergo a new phase of gonad maturation and emigration.
\end{abstract}

KEY WORDS: Ventiella sulfuris $\cdot$ Reproduction $\cdot$ Hydrothermal vents $\cdot$ Vent fidelity $\cdot$ Biomarker

\section{INTRODUCTION}

Ventiella sulfuris was described by Barnard \& Ingram (1990) and is considered to be a vent-endemic derivative of the widespread deep-sea genus Schisturella. Of the $\sim 100000$ amphipod specimens examined by Barnard and Ingram from eastern Pacific hydrothermal vents, $>98 \%$ were $V$. sulfuris. Although abundant at East Pacific Rise (EPR) vents, little is known of the species' ecology or adaptations to the vent environment. Amphipods have frequently been recorded as a dominant component of the macrofauna of vents (Sheader et al. 2000, 2004), though none have been found to utilise endosymbionts; all are heterotrophs, thought to feed predominantly on bacterial detritus (Vinogradov 1993). Despite their abundance, amphipods remain one of the least studied components at hydrothermal vents (Vinogradov 1993). To date, the reproductive ecology of only 2 species of vent-endemic amphipods has been described (Sheader et al. 2000, 2004), and, whilst this has demonstrated that interspecific differences in reproductive ecology occur, the full range of adaptations (to particular vent habitats, or to different categories of vent) will only become apparent as more species are studied.

Hydrothermal vents are short-lived features, with a discontinuous distribution (Van Dover 2000); at the EPR, vent habitats undergo a relatively rapid hydrothermal cycle (days to decades) (Haymon et al. 1993, Shank et al. 1998). Although individual vents cycle at different rates, in general, older vents would be expected to exhibit reduced fluid flow, and hence the chemosynthetic food resource would decline with time. We hypothesise that, as vents age, with a reduc- 
tion in the overall food resource, the population abundance of Ventiella sulfuris would decline. Although population size at a given vent habitat may, in part, be determined by the overall food supply, food limitation at the level of the individual may not necessarily vary between vents of different ages, and therefore population structure and reproductive parameters may be dependent on site-specific biotic and abiotic factors rather than vent age-related processes. We explore this idea by comparing populations at different spatial scales, varying from within individual vent sites (samples separated by metres), between vent sites in a given field (separated by $10^{2}$ to $10^{4} \mathrm{~m}$ ) and between vent fields (separated by $27^{\circ}$ of latitude).

Despite the phylogenetic constraints (e.g. limited dispersive ability, low fecundity, the production of relatively large eggs and obligate brooding with direct development), amphipods can show a high degree of within- and between-species reproductive and population variation. For example, populations may differ in the body size at which maturity is achieved, longevity, whether they are periodic or continuous breeders, the number and size of eggs produced per brood, the number of broods per female, male/female morphology and relative size, and sex ratio (Sheader 1983, Johnson et al. 2001). Within populations these characteristics may change in response to environmental fluctuations in factors such as temperature and food quantity/quality, as well as to any other factor that might impact the organism's allocation of energy resources within its overall energy budget (Sheader 1983, Johnson et al. 2001).

In shallow-water systems there has been extensive use of amphipod population models in lethal (Bat \& Raffaelli 1998, Roddie \& Thain 2002) and sublethal toxicity testing (Maltby \& Naylor 1990, Ford et al. 2003). In assessing sublethal impact in field populations, measures of reproductive output and embryo survival are favoured indicators of environmental perturbation or may be used as biomarkers of pollution (Ford et al. 2003, Wiklund \& Sundelin 2004). Hydrothermal vents are spatially and temporally variable environments in terms of, for example, flow rate, temperature, oxygen and chemical composition, all factors affecting the amount and type of food available as well as the occurrence of potentially toxic materials. Such variation might be expected to result in measurable betweensite differences in amphipod populations, though this would be dependent on the scale of spatial motility. At EPR hydrothermal vent sites, Van Dover (2002) considered that the amphipod Ventiella sulfuris, although often dominant in mussel beds, was highly motile and unlikely to display long-term fidelity to a given patch of mussels, and suggested that numerical dominance at sites may be ephemeral on the scale of hours. On a larger spatial scale, between vent sites, genetic struc- ture analysis of $V$. sulfuris indicates that the species migrates along the ridge axis in a stepping stone manner (France et al. 1992).

Ventiella sulfuris is associated with a range of vent habitats, including tube-worm and mussel beds, and can also be found swimming immediately above such habitats. The present study uses quantitative and qualitative mussel bed samples collected at 6 vent sites located at 2 vent fields at the EPR. The vent sites differ in age (measured as the time since volcanic activity last occurred), which influences the rate of venting, which in turn determines the trophic resources available. The temperature of the fluid venting through the mussel beds is site dependent (though usually $<10^{\circ} \mathrm{C}$ ), as is the chemical composition of the venting fluid.

Our study had 2 main objectives, firstly, to describe the reproductive ecology and population dynamics of this lysianassoid amphipod and, secondly, to determine how populations differ between vents over varying spatial scales and in relation to vent age. We examine how this successful vent-endemic amphipod has adapted its reproductive and population ecology to the dynamic and spatially disjunct nature of the vent environment. We determine whether there is variation in its adaptive response and, if so, at what spatial or temporal scale. It may be that the species selects and occupies a well-defined habitat, similar at each vent site, and therefore demonstrates little spatial or temporal variation between populations. Low between-site population variation would also result if motility were high with frequent movement of individuals between sites. Alternatively, if exchange between sites were low, then site populations may adjust or modify their reproductive and population ecology in response to environmental conditions at each vent, resulting in significant differences between sites. If this is the case, then amphipod populations may prove to be useful indicators of vent conditions (e.g. fluid flow, temperature, $\mathrm{pH}$, oxygen, metal, sulphide, trophic resources) integrated over the short term, in much the same way as certain shallow-water amphipod species are currently used as non-specific biomarkers of environmental condition or quality.

\section{MATERIALS AND METHODS}

Study sites. Details and maps of the vent fields and sites used in the current mussel bed study were given by Van Dover (2002, 2003). Two vent fields were sampled: the $9^{\circ} 50^{\prime} \mathrm{N}$ northern East Pacific Rise field (NEPR) and the $17^{\circ} 30^{\prime} \mathrm{S}$ southern East Pacific Rise field (SEPR). NEPR amphipod samples were collected from 3 distinct vent sites: Biovent, East Wall and Train Station. At SEPR, samples were collected at 3 vent 
sites: Oasis, Rehu Marka and Animal Farm. All sites are located on the EPR along the axial caldera that is the active spreading centre. Regular monitoring of these sites has allowed the age of each vent at the time of sampling to be estimated as the time interval since the last volcanic eruption. Of course, mussel beds take time to become established following eruptions, and so the age of each mussel bed will be somewhat less than the age of the vent. Mussel bed water temperature estimates were given by Van Dover (2002) for SEPR sites, or were estimated for NEPR sites using data gathered over the sampling period employing in situ 'hobo' probes. Site details are given in Table 1.

The NEPR and SEPR vent fields are separated by $>27^{\circ}$ of latitude. At NEPR, Biovent is $~ 800 \mathrm{~m}$ from East Wall and $\sim 2515 \mathrm{~m}$ from Train Station; East Wall and Train Station are separated by $\sim 1715 \mathrm{~m}$. At SEPR, Rehu Marka and Oasis are $850 \mathrm{~m}$ apart, with Animal Farm $\sim 133 \mathrm{~km}$ to the south.

At the SEPR sites, fluid flow, mussel maturity and mussel condition (productivity index) indicate that the sites can be ranked in terms of venting activity, with Oasis > Rehu Marka >> Animal Farm (Van Dover 2002).

Twenty-seven additional qualitative samples, collected by suction sampler from a range of NEPR (between 8 and $13^{\circ} \mathrm{N}$ ) vent habitats (Tevnia beds, Riftia beds, amongst stauromedusae, in areas of new flow, chimneys, adjacent sulphur-rich sediment, vent edge, extinct vent), were processed to aid interpretation of the mussel bed data; 2000 Ventiella sulfuris were examined. These samples were collected during November 2003, at depths of 2550 to $2620 \mathrm{~m}$, using the submersible 'Alvin'.

Sample collection and processing. The sampling procedure is detailed in Van Dover (2003). Six quantitative replicate samples and 2 qualitative samples of mussels Bathymodiolus thermophilus were collected at each NEPR site during November 1999. SEPR sites were sampled in February 1999 (SEPR); we collected 4 quantitative samples and 2 qualitative samples at Rehu Marka and 2 quantitative samples and 6 qualitative samples at Oasis. Mussels beds, approximately 50 to $100 \mathrm{~m}$ across, occupied low-temperature $\left(<10^{\circ} \mathrm{C}\right)$ flow zones adjacent to cracks in the basalt lava. Each quantitative sample contained a variable mussel volume over a constant area of $531 \mathrm{~cm}^{2}$. Samples were washed through a $63 \mu \mathrm{m}$ aperture sieve, preserved in buffered $10 \%$ formalin, stored in $70 \% \mathrm{EtOH}$ and subsequently twice-sorted under a dissecting microscope to remove all organisms. Specimens of Ventiella sulfuris were separated.

Analysis of amphipod material. A general account of amphipod reproductive ecology and analytical methodology is given in Sheader et al. (2000). Where possible, 200 amphipods were selected randomly from each sample for detailed analysis. Additional females with late oocytes were analysed to provide sufficient data on brood size.

Growth stages can be determined by measuring body length. Individuals were preserved in a variety of postures, making body length for many specimens difficult to measure accurately. The problem was resolved by selecting an easily measurable body structure, linearly related to body length. The length of the dorsal margin of Pleonite 1 proved to be such a structure for this species and was therefore measured (to the nearest $0.01 \mathrm{~mm}$ ) and used as an index of body length. This was related to actual body length (anterior of head to distal tip of telson) by accurately measuring 100 individuals, selected to cover the complete size range present in samples.

Sexual dimorphism in this species is not marked. However, at all but the smallest stages, sexes could be separated by the presence of developing oostegites (brood plates) in the female and developing penes in the male. For females, oostegites develop on the bases of Peraeopods 2 to 5 ; the length of the oostegite of Peraeopod 4 was recorded as an indicator of oostegite development (Sheader et al. 2000); the selection of Peraeopod 4 was arbitrary. The occurrence of developing marginal setae below the oostegite exoskeleton (indicative of the moult prior to maturity) was noted,

Table 1. Study site characteristics (NEPR: northern East Pacific Rise; SEPR: southern East Pacific Rise)

\begin{tabular}{|c|c|c|c|c|}
\hline Location & Position & $\begin{array}{l}\text { Depth } \\
\text { (m) }\end{array}$ & ${ }^{\circ} \mathrm{C}$ above ambient & $\begin{array}{c}\text { Estimated age } \\
\text { (yr) }\end{array}$ \\
\hline NEPR & $9^{\circ} \mathrm{N}$ & & (ambient $\sim 2^{\circ} \mathrm{C}$ ) & \\
\hline Biovent & $\begin{array}{l}9^{\circ} 50.992^{\prime} \mathrm{N}, \\
104^{\circ} 17.592^{\prime} \mathrm{W}\end{array}$ & 2494 & $2-4$ & $>8$ \\
\hline East Wall & $\begin{array}{l}9^{\circ} 50.534^{\prime} \mathrm{N}^{\prime} \\
104^{\circ} 17.520^{\prime} \mathrm{W}\end{array}$ & 2499 & $1-8$ & 4 \\
\hline Train Station & $\begin{array}{l}9^{\circ} 49.645^{\prime} \mathrm{N} \\
104^{\circ} 17.357^{\prime} \mathrm{W}\end{array}$ & 2491 & $2-5$ & 5 \\
\hline SEPR & $17-18^{\circ} \mathrm{S}$ & & (ambient $\sim 1.7^{\circ} \mathrm{C}$ ) & \\
\hline Rehu Marka & $\begin{array}{l}17^{\circ} 24.940^{\prime} \mathrm{S} \\
113^{\circ} 12.190^{\prime} \mathrm{W}\end{array}$ & 2581 & 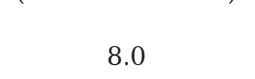 & $10-16$ \\
\hline Oasis & $\begin{array}{l}17^{\circ} 25.394^{\prime} \mathrm{S} \\
113^{\circ} 12.323^{\prime} \mathrm{W}\end{array}$ & 2582 & 4.5 & 6 \\
\hline Animal Farm & $\begin{array}{l}18^{\circ} 36.429^{\prime} \mathrm{S} \\
113^{\circ} 23.995^{\prime} \mathrm{W}\end{array}$ & 2675 & 0.1 & $20-30$ \\
\hline
\end{tabular}


though females with fully developed marginal oostegite setae (indicative of brooding mature females) were absent from the mussel bed samples. For males, penis length was recorded. Oostegite and penis development provide useful indicators of the stage of reproductive development of individuals within populations (Sheader et al. 2000).

All 200 individuals at each site were dissected, and gonads were removed for further examination when present. The ovaries lie along the dorso-lateral surface of the gut within the peraeon and are attached to the gut by a series of connective tissue strands. The ovaries are linear with small germinal cells (oogonia) along their dorsal margin and (usually) a single row of oocytes arranged along the ovary. As the oocytes mature, the 2 ovaries come into contact along their dorsal margins, filling the space between the heart and the gut. The ovaries were dissected from the surface of the gut under a low-power stereomicroscope, the ovaries and oocytes were measured, and the total number of oocytes per ovary was counted. Oocytes develop as a cohort and were very similar in size in any 1 individual; 5 oocytes were considered sufficient to provide a representative measurement of size. For each oocyte, size was expressed as a mean of maximum and minimum diameters.

The testes lie along the dorso-lateral surface of the gut within the peraeon, and, as with the ovaries, are attached to the gut by connective tissue strands. Each vas deferens runs posteriorly along the gut to open at a penis at the base of Peraeopod 7. The testes were dissected from the gut surface for measurement, and the presence/absence of mature spermatozoa in the vasa deferentia was recorded.

During dissection, the presence of food in the gut of each amphipod was noted, as was the degree of distension of the gut diverticula, indicating the accumulation of storage products (Sheader et al. 2000); the occurrence of lipids was determined by staining with Sudan Black.

Determination of growth stages. The body length, as determined by the derived relationship with the length of Pleonite 1, varied between 1.12 and $6.49 \mathrm{~mm}$. Size-frequency distributions for Ventiella sulfuris from individual vent sites and for the whole survey produced a consistent and clear series of peaks, which were confirmed by probit analysis. These regularly spaced peaks were assumed to represent growth stages (instars) (Sheader et al. 2000, 2004). The separation of individuals into growth stages proved difficult, since there was significant size overlap between adjacent stages. Separation was achieved by using the number of podomeres (divisions) in the exopod of Pleopod 1. It has been demonstrated that, in some amphipods, 1 new podomere is added to each pleopod ramus at each moult (Sheader 1981, Ikeda 1990, Yamada et al. 2004), potentially providing a marker for instar number. In the $V$. sulfuris examined, modes in the size-frequency peaks corresponded exactly to the number of podomeres in the exopod ramus of Pleopod 1, suggesting that each successive growth stage is characterised by a particular number of exopod divisions in this species. The number of podomeres has therefore been used to delineate growth stage (with the number of exopod divisions equal to growth stage number, though note that this number is not necessarily equivalent to instar number), with up to 13 stages recorded (G6 to G18). The stages prior to G6 were not recorded in samples and would include marsupial (usually 2 stages) and possibly early free-living juveniles.

As growth stages were clearly defined, they were used in subsequent within- and between-site comparisons and in the interpretation of reproductive ecology, since growth stages are more closely related to reproductive development than absolute body length (Sheader et al. 2000, 2004).

\section{RESULTS}

\section{Abundance}

Although each mussel bed sample covered an area of $531 \mathrm{~cm}^{2}$, sample volume varied between 1.3 and 8.01 . Since the mussel bed habitat is 3-dimensional, the amphipod abundance was expressed per unit volume. The mean abundance differed significantly between the 5 sites $\left(F_{4,19}=14.20, \mathrm{p}<0.001\right)$ and was related to vent age (Fig. 1); pairwise comparisons showed no significant difference between the 3 youngest vents, East Wall, Train Station and Oasis, but exhibited significant difference between these and the 2 oldest vents (supporting Ventiella sulfuris), Rehu Marka ( $\mathrm{p}<0.001)$ and Biovent $(\mathrm{p}<0.001)$. There were no $V$. sulfuris recorded at Animal Farm (SEPR), the oldest site sampled, where flow rates were low, the temperature was just above ambient and the mussel population was in poor condition (Van Dover 2002).

\section{Determination of body size}

There was a high correlation $\left(\mathrm{r}^{2}=0.986, \mathrm{p}<0.001\right)$ between total body length (anterior-most tip of the head to the distal tip of the telson) and the length of the dorsal margin of Pleonite 1. The regression was positive and linear, permitting the measured Pleonite $1(P$, $\mathrm{mm}$ ) values to be converted to total body length ( $L_{\text {, }}$ $\mathrm{mm}$ ) using the equation: $P=0.150 L+0.009$. 


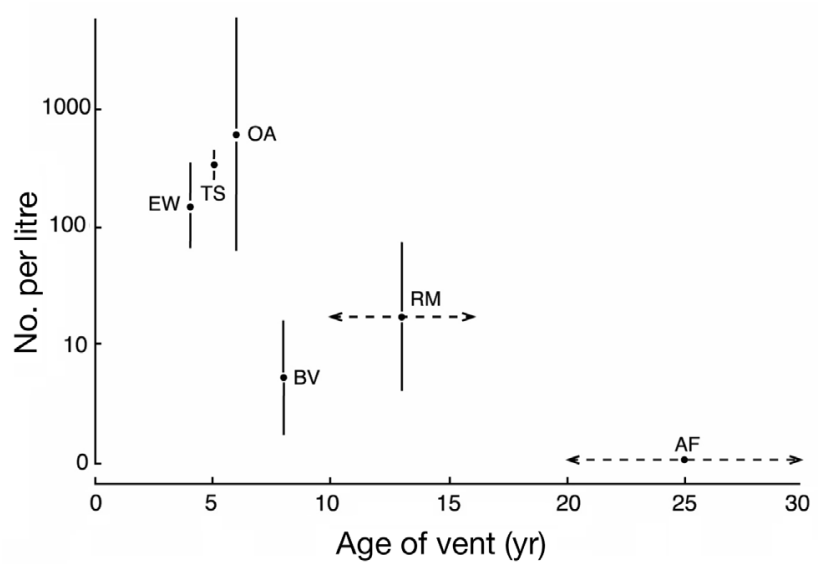

Fig. 1. Ventiella sulfuris. Mean abundance $( \pm 1 \mathrm{SD})$ per litre at vents of different age. Dashed line represents the range of estimated age (BV: Biovent; EW: East Wall; TS: Train Station; OA: Oasis; RM: Rehu Marka; AF: Animal Farm)

\section{Within-site and between-site variations in growth- stage frequency}

The similarity of growth-stage frequencies, both within and between sites, was assessed using PRIMER v5 (Clarke \& Gorley 2001). The Bray-Curtis similarity index was applied to the transformed (square root) growth-stage abundance data. Transformation reduced the impact of data from samples where Ventiella sulfuris abundance was high, giving a better comparison of the proportional distribution of individuals between growth stages. The results are expressed as an MDS (multidimensional scaling) ordination using the group averaging method (Fig. 2). Six quantitative replicates were used for each of the NEPR sites, and 4 replicates were used for each of the SEPR sites.

Samples from each site were clustered, indicating high within-site similarity in population structure. The within-site similarity (SIMPER subroutine of PRIMER v5) was high (Train Station: 78\%; Biovent: $85 \%$; Oasis: 86\%; Rehu Marka: $77 \%$; East Wall: 68\%). East Wall samples were less tightly clustered than those at the other sites.

Between-site differences in population structure were tested using analysis of similarity (ANOSIM subroutine of PRIMER v5). The null hypothesis was 'that there were no populationstructure differences between sites'. The global value of the R-statistic for these data was 0.625 , larger than expected by chance, and the null hypothesis was rejected at the $\mathrm{p}=$ 0.001 level. The ANOSIM confirmed significant between-site differences in population structure.
Pairwise site comparisons are given in Table 2. Where there are significant differences, the R-statistic gives an absolute measure of site separation $(R>0.75$, sites well separated; $R=0.5$ to 0.75 , sites overlapping but clearly different; $R=0.25$ to 0.5 , sites broadly overlapping but separable; $R<0.25$, sites barely separable).

Oasis had the greatest number of growth stages of any site, with all stages present up to G18. Rehu Marka had a markedly reduced number of growth stages, with all instars up to G14 present. East Wall samples exhibited the greatest within-site variation, indicating greater population heterogeneity; all stages up to G17 were recorded. Oasis and Biovent sites showed the highest similarity in growth-stage frequency distribution (84\% similar, SIMPER subroutine of PRIMER v5). The lowest similarity values were recorded between Train Station and Rehu Marka (31\% similar).

Between-field differences in growth-stage abundance similarities were tested between NEPR and SEPR using ANOSIM. Differences between vent fields were significant $(\mathrm{R}=0.46, \mathrm{p}<0.001)$. NEPR stations were similar at $77 \%$, SEPR stations at $73 \%$, with NEPR and SEPR similar at $64 \%$.

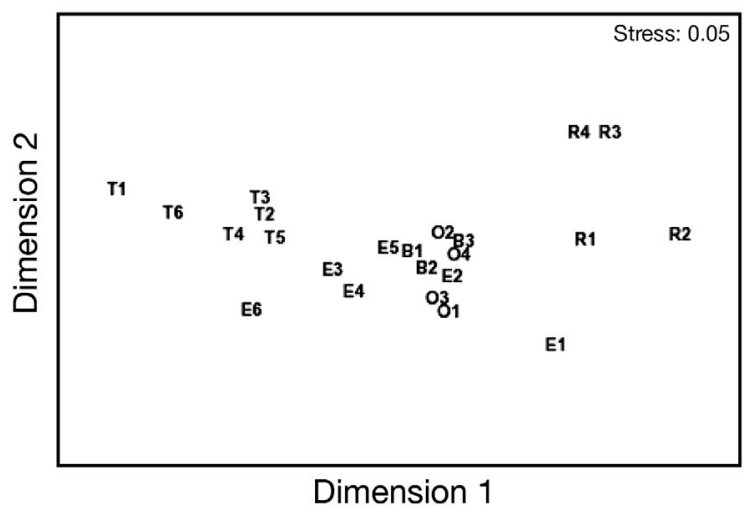

Fig. 2. Ventiella sulfuris. Multidimensional scaling ordination of growth-stage composition (see 'Materials and methods') from replicate samples at different vent sites (B: Biovent; E: East Wall; T: Train Station; O: Oasis; R: Rehu Marka)

Table 2. Ventiella sulfuris. Pairwise comparison of the population structure (relative abundance of growth stages) at vent sites. Top right: R-values for ANOSIM (probability values in parentheses; n.s.: not significant). Bottom left: average similarity in population structure, in percent (SIMPER subroutine of PRIMER)

\begin{tabular}{|lccccc|}
\hline & Biovent & East Wall & Train Station & Oasis & Rehu Marka \\
\hline Biovent & & 0.136 (n.s.) & $0.963(0.012)$ & 0.296 (n.s.) & $0.926(0.029)$ \\
East Wall & 72.9 & & $0.548(0.002)$ & 0.143 (n.s.) & $0.778(0.005)$ \\
Train Station & 51.2 & 60.7 & & $1.000(0.005)$ & $1.000(0.005)$ \\
Oasis & 84.2 & 71.6 & 50.0 & 63.5 & $0.948(0.029)$ \\
Rehu Marka & 64.9 & 50.5 & 31.1 & 63.5 & \\
\hline
\end{tabular}


The analysis of growth-stage frequency indicated high within-site similarity. Differences in population structure between most vent/site pairs and betweenvent fields were significant. Differences in growthstage structure of male and female components of site populations are described in the following sections.

\section{Female development}

Development of oostegites

Oostegite data from all 5 sites showed that there were 5 clearly defined oostegite development stages (OS1 to OS5), easily separated by differences in oostegite length (Peraeopod 4). The range in oostegite length values at each stage were: OS1, 20-45 $\mu \mathrm{m}$; OS2, 50-100 $\mu m_{i}$ OS3, 110-190 $\mu m_{i}$ OS4, 200-265 $\mu \mathrm{m}$; and OS5, 315-530 $\mu \mathrm{m}$.
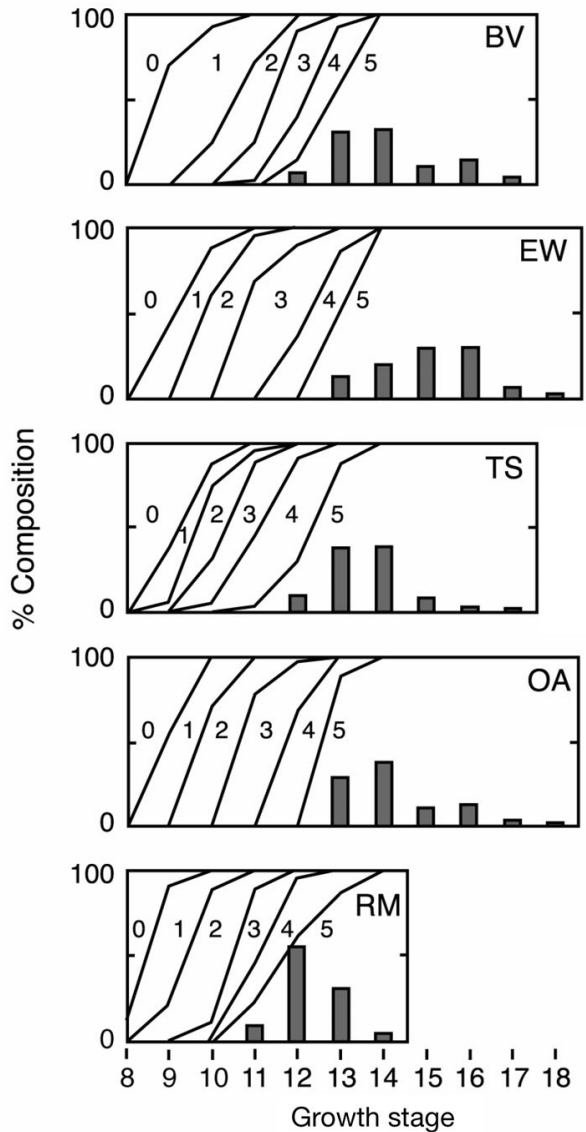

Fig. 3. Ventiella sulfuris. Change in the percentage composition by oostegite stage at each growth stage for each vent site. Numbers (0 to 5) represent Oostegite Stages 0 to 5 (OS0 to OS5). Histograms show percentage distribution of OS5 females among growth stages (BV: Biovent; EW: East Wall; TS:

Train Station; OA: Oasis; RM: Rehu Marka)
Mature females were absent from mussel bed samples at all 5 sites, and therefore the final oostegite stage (OS6) was not observed. In OS5 females, marginal setae could be seen beneath the exoskeleton on the distal half of each oostegite. At the next moult, these setae would be free to extend and interlock to form the marsupium, characteristic of mature females.

The growth stage at which females begin to develop oostegites varied both within vent populations and, to a greater extent, between sites (Fig. 3), with OS1 females first appearing at G8 to G11 (2.7 to $4.3 \mathrm{~mm}$ body length). Females progressed through the oostegite stages at successive moults, achieving OS5 at G11 to G14 (4.3 to $5.4 \mathrm{~mm}$ body length).

Mature females (characterised by a fully developed marsupium with setose oostegites) were not found at any of the vent-site mussel beds. However, OS5 females continued to be recorded up to G14-G18 (5.4 to $6.4 \mathrm{~mm}$ body length), though the highest growth stage achieved was site dependent (Fig. 3). With no OS4 individuals present in populations at a high enough growth stage to supply these large OS5 females, the source of these is open to conjecture.

If movement of growth stages between vents were high, then it would be expected that the relationship between growth stage and oostegite stage would be similar at adjacent sites; this is clearly not the case (Fig. 3, compare SEPR Oasis \& Rehu Marka).

Although the pattern of female maturation was ventsite dependent, there was no evidence from the data that the pattern was related to vent age; modal growth stage at OS5 did not correlate significantly with vent age (Spearman's rank correlation, $r_{s}=0.6$, not significant).

\section{Development of oocytes}

Ovaries could first be detected at OS1 (minimum was G8 at Rehu Marka and G9 at the other sites). The dorsal region of each ovary consisted of a thin band of germinal tissue with oogonia (these were distinguished by their location in the ovary, close to the dorsal germinal zone, and their relatively constant small size). These were present in all ovaries and had a mean diameter $( \pm \mathrm{SD})$ of $19.8 \pm 1.6 \mu \mathrm{m}(\mathrm{n}=50)$.

As females progressed through the oostegite stages, the oocytes increased in size, with a marked increase at OS5 (Fig. 4-the same pattern of oocyte size with oostegite stage was found for all vent sites, and data are therefore pooled). For each female, a cohort of oocytes developed synchronously, with little variation in oocyte size within the ovaries at any one time. Vitellogenesis, as indicated by granular yolk deposited in the cytoplasm, was initiated at OS4 and continued 

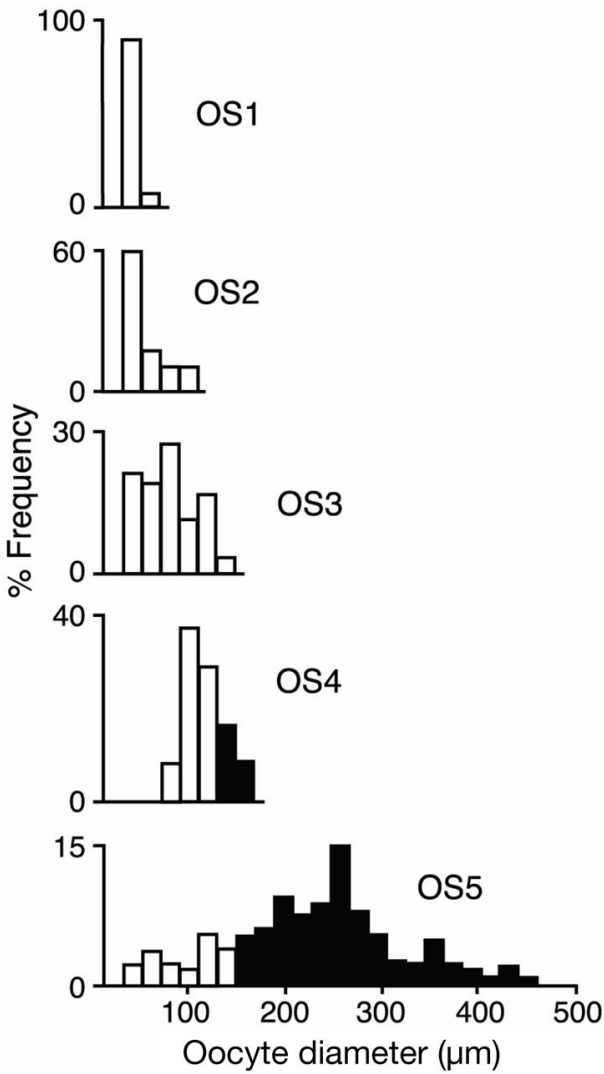

Fig. 4. Ventiella sulfuris. Frequency distribution of females with different oocyte size classes at each oostegite stage (OS1, $\mathrm{n}=146 ;$ OS2, $\mathrm{n}=112 ;$ OS3, $\mathrm{n}=122 ;$ OS4, $\mathrm{n}=96$; OS5, $\mathrm{n}$ =456). Filled bars: females containing oocytes undergoing vitellogenesis

through OS5, giving a maximum oocyte diameter of around $450 \mu \mathrm{m}$.

It is interesting to note that a small proportion of OS5 females at each site had ovaries containing a cohort of small oocytes (<90 $\mu$ m diameter), with no large oocytes present. There were no females with cohorts of small oocytes (<90 $\mu$ m diameter) at OS4 (Fig. 4).

In OS5 females carrying late oocytes, the ovary was distended and completely filled the paraeon, extending from the anterior margin of the first peraeon segment to the posterior margin of the first pleon segment. At this late OS5 stage, the gut was compressed by the ovaries and contained no food. At all other stages (including early OS5), particulate detritus was present in the narrow gut, but at no stage was there indication of distension of the digestive diverticula; the digestive diverticula, when stained with Sudan Black, revealed relatively little stored lipid.

The number of eggs produced (brood size) is usually closely related to the number of late-stage oocytes (Sheader et al. 2004). This, in turn, is determined by the number of early oocytes generated at OS1 and the subsequent pattern of resorption. Vent sites could be separated into 3 groups according to their mean oocyte numbers at OS1 (Fig. 5). East Wall and Oasis were characterised by large numbers of early oocytes (means 80.5 and 82.0, respectively); Train Station and Biovent, by intermediate numbers (means 63.7 and 62.5, respectively); and Rehu Marka, by low numbers (mean 48.3).

Oocyte resorption, as indicated by the change in mean oocyte number between OS1 and OS5 females, was high at Oasis, Train Station and East Wall ( 45\%), but lower at Biovent ( 37\%) and Rehu Marka ( 35\%). Between-site differences in oocyte resorption have little impact on the ranking of sites (by oocyte number) by OS5, with Oasis and East Wall females producing the highest mean numbers of late oocytes (ca. egg numbers) per brood and Rehu Marka producing the lowest (Fig. 5). The mean body length of OS5 females was positively correlated with the number of oocytes generated at OS1 (Spearman's rank correlation, $\mathrm{r}^{2}=$ $0.742, \mathrm{p}<0.05)$ and the number of late oocytes remaining at OS5 $\left(\mathrm{r}^{2}=0.699, \mathrm{p}<0.05\right)$.

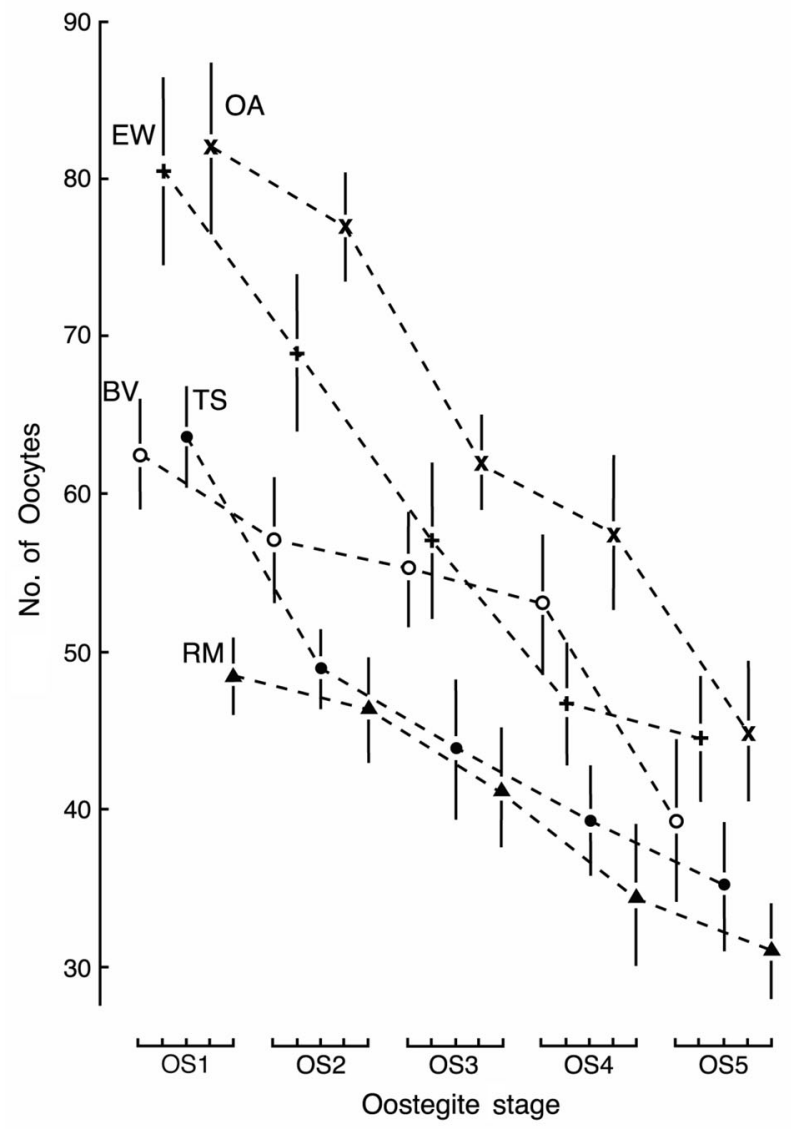

Fig. 5. Ventiella sulfuris. Change in the mean number of oocytes per female $( \pm 1 \mathrm{SD})$ with oostegite stage (OS1 to OS5) at each vent site (BV: Biovent; EW: East Wall; TS: Train Station; OA: Oasis; RM: Rehu Marka) 
By OS5, when vitellogenesis was in its final stages, oocyte resorption had ceased, and the number of oocytes closely approximated the number of eggs (brood size) that would be produced at the next moult (Sheader et al. 2004). The mean number of late oocytes ('brood size') for all vent sites combined is positively correlated with growth stage (Spearman's rank correlation, $\mathrm{r}_{\mathrm{s}}=+1.000, \mathrm{p}<0.001$ ) (Fig. 6). The situation is less clear at individual sites, which differ from one another in the range of growth stages containing OS5 females (Fig. 6).

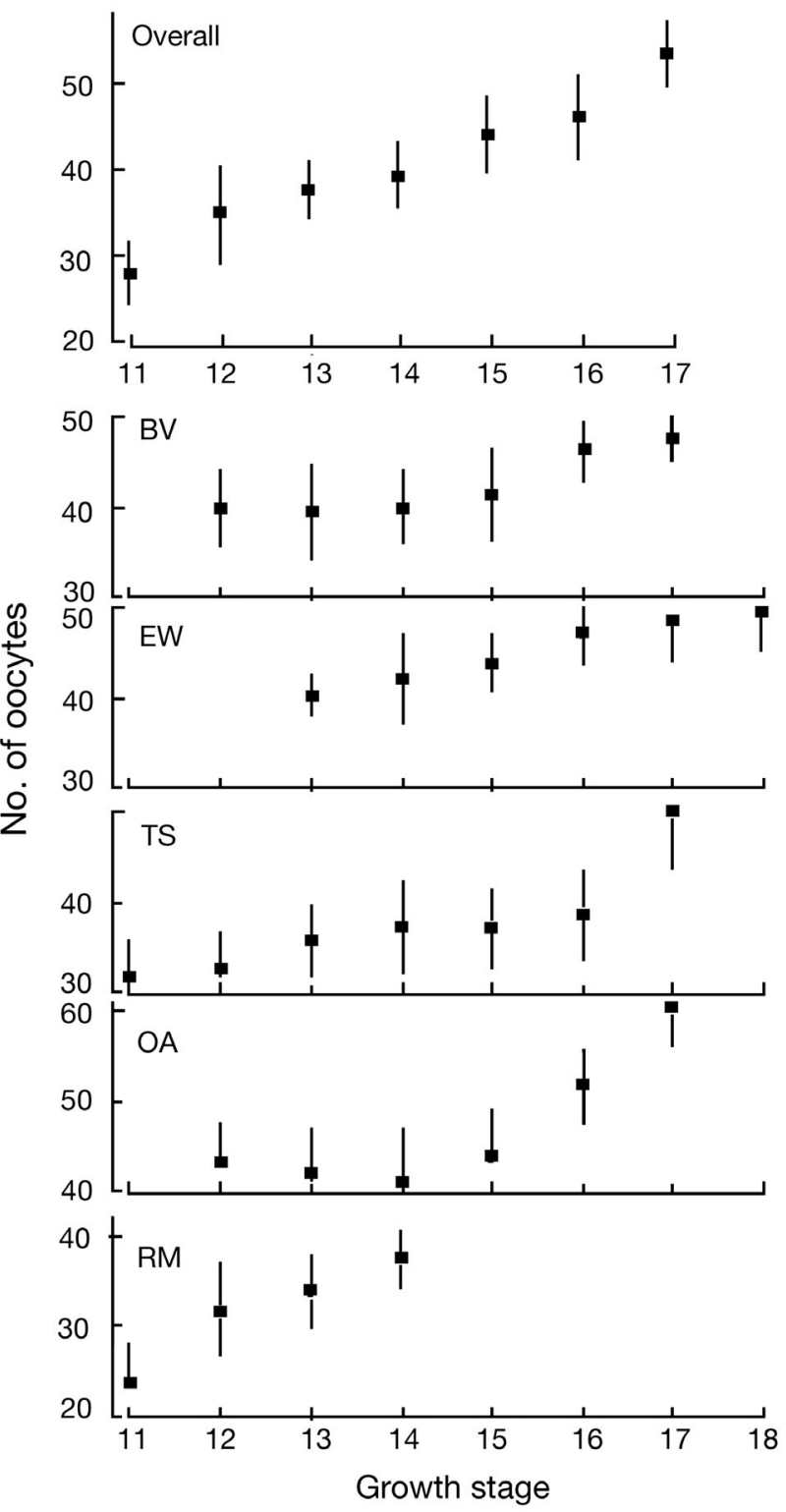

Fig. 6. Ventiella sulfuris. Relationship between the number of oocytes per OS5 female $( \pm 1 \mathrm{SD})$ and growth stage at each vent site and for all sites combined (BV: Biovent; EW: East Wall; TS: Train Station; OA: Oasis; RM: Rehu Marka)
Female size

Sexes were separable from G8 (2.7 mm body length), with OS5 females reaching a maximum growth stage of G18 (6.4 mm body length; Fig. 3). With the absence of mature females in mussel bed samples, the population structure of late-stage (OS5) females was considered to be representative of the mature female component and has been compared at the 5 vent sites.

The mean length of OS5 females at the 5 sites differed $\left(F_{4,529}=34.286, \mathrm{p}<0.001\right)$. Mean body length $( \pm \mathrm{SD})$ was highest $(5.630 \pm 0.256 \mathrm{~mm})$ at East Wall (EW) and lowest $(4.731 \pm 0.217 \mathrm{~mm})$ at Rehu Marka (RM), with intermediate values for Train Station (TS) $(5.251 \pm 0.224 \mathrm{~mm})$, Biovent $(\mathrm{BV})(5.425 \pm 0.226 \mathrm{~mm})$ and Oasis (OA) (5.375 $\pm 0.335 \mathrm{~mm})$. Pairwise comparisons between sites indicated that the difference between the means was significant for all pairs except Biovent and Oasis (2-tailed z-test: BV vs. RM, EW vs. TS, EW vs. OA, EW vs. RM, TS vs. RM, OA vs. $\mathrm{RM}-\mathrm{p}<0.001$; $\mathrm{BV}$ vs. $\mathrm{EW}-\mathrm{p}=0.007$; $\mathrm{BV}$ vs. $\mathrm{TS}-\mathrm{p}=0.016 ;$ TS vs. OA $-\mathrm{p}=0.033 ; \mathrm{BV}$ vs. OA $-\mathrm{p}$ $=0.558)$.

Although female size was clearly vent-site dependent, there was no clear relationship to vent age (Spearman's rank correlation, $\mathrm{r}_{\mathrm{s}}=0.6$, not significant).

\section{Male development}

Penis buds were first apparent at G8. Penes developed over a series of moults to reach a maximum length. The testes appeared to be mature at this late developmental stage, but spermatozoa were evident in the vasa deferentia (indicative of mature males) of only a small proportion $(<1 \%)$ of these. With this in mind, we refer to these as 'late stage' (LS) rather than mature males. LS males first appeared in samples at G11 to G13 (site dependent), continuing to G13 to G17 (site dependent).

The difference in the mean body length of LS males at the 5 sites was statistically significant $\left(F_{4,484}=20.88\right.$, $\mathrm{p}<0.001)$. Pairwise comparison between sites indicated that differences between means were significant for all pairs of sites (2-tailed $z$-test, p < 0.001), except Eastwall vs. Biovent (2-tailed $z$-test, $p=0.657$ ). Mean body length $( \pm \mathrm{SD})$ for LS males was highest at Biovent $(5.50 \pm 0.24 \mathrm{~mm})$, lowest at Rehu Marka (4.62 \pm $0.21 \mathrm{~mm}$ ), with intermediate values at the remaining stations (East Wall $-5.43 \pm 0.24 \mathrm{~mm}$; Train Station $5.19 \pm 0.21 \mathrm{~mm}$; Oasis $-5.15 \pm 0.28 \mathrm{~mm}$ ).

Although male size was vent-site dependent, there was no apparent relationship to vent age (Spearman's rank correlation, $r_{s}=0.3$, not significant). All males examined had fine detritus in the gut. 


\section{Sexual dimorphism and sex ratio}

In the original description of Ventiella sulfuris, Barnard \& Ingram (1990) found little morphological difference between males and females, though none of the specimens described were fully mature. They found that the Antenna 1 accessory flagellum basal article to be as long as Article 1 of the primary flagellum in males, but shorter in females. The full extent of sexual dimorphism in this species can only be determined when fully mature specimens are available to compare.

Earlier sections of this study have demonstrated between-site differences in the mean body length of late-stage females (OS5) and late-stage males (LS). Within-sites, the relative size of LS males and OS5 females varied, with males significantly smaller than females at East Wall (2-tailed $z$-test, $p=0.002)$ and at Oasis $(p<0.001)$. At the remaining sites (Biovent, Train Station, Rehu Marka) differences between LS male and OS5 female body length were not significant.

Sexes were separable from G8, and the relative proportion of males to females (sex ratio) was found to vary between sites (Fig. 7). The departure from a sex ratio of 1:1 was tested using $\chi^{2}$ with Yates' correction. Oasis and Biovent showed no significant departure from a sex ratio of 1:1. At East Wall $\left(\chi^{2}=6.15, p<0.05\right)$ there was a significant excess of males, and at Train Station $\left(\chi^{2}=\right.$ 12.95, $\mathrm{p}=<0.001)$ and Rehu Marka $\left(\chi^{2}=4.24, \mathrm{p}=\right.$ $<0.05)$ there was a significant excess of females.

Sex ratio was vent-site dependent, and was not related to vent age (Spearman's rank correlation, $\mathrm{r}_{\mathrm{s}}=$ 0.7 , not significant).

\section{Non-mussel bed qualitative samples}

In the qualitative samples collected from other vent habitats, Ventiella sulfuris was recorded from Tevnia and Riftia beds, amongst stauromedusae (towards the vent margins), on sulphur-rich sediment adjacent to vents and at sites at the extreme periphery of the vents (vent margin). None were found in samples collected from an area of new flow or at a chimney. At all sites other than the vent margin, a range of immature male and female growth stages were recorded, with populations appearing similar in structure to those found at mussel beds.

The vent margin sample (Genesis vent site, $12^{\circ} 48.656^{\prime} \mathrm{N}, 103^{\circ} 56.437^{\prime} \mathrm{W}$ ) differed from other qualitative vent-habitat samples in that it contained only mature males and females, together with a single late immature (OS5) female. Of the 11 amphipods, 4 were mature females (G18, G19, G19 \& G20) and 6 mature males (G11, G11, G12, G14, G14 \& G19). The vasa deferentia of the males were packed with spermatozoa.

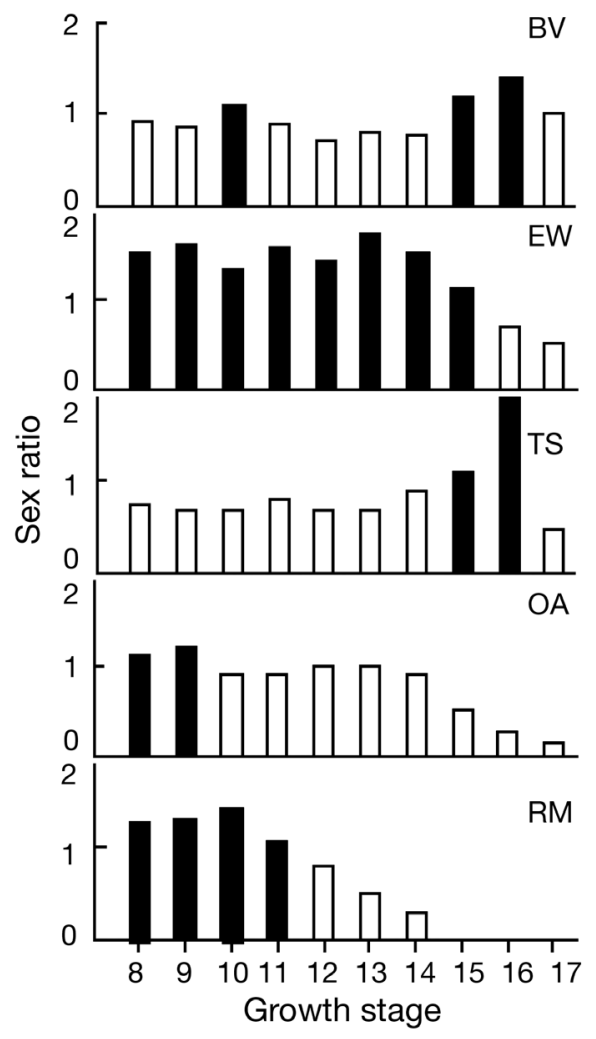

Fig. 7. Ventiella sulfuris. Change in sex ratio (males per female) after G8 at each vent site. Filled histograms indicate values >1 (BV: Biovent; EW: East Wall; TS: Train Station; OA: Oasis; RM: Rehu Marka)

The mature females all had well-developed oostegites with short marginal setae (Peraeopod 5 oostegite: 1.16 to $1.42 \mathrm{~mm}$ long). Of the 4 mature females, 3 carried eggs in the marsupium, and all had a new cohort of oocytes developing in the ovary, although these were still small (range: 49 to $55 \mu \mathrm{m}$ ). One female carried early stage eggs (mean diameter: $516 \mu \mathrm{m}$ ) and 2 carried eggs with fully formed embryos close to hatching (mean diameters: 673 and $667 \mu \mathrm{m}$ ). Based on data from these few females, eggs showed an increase in volume during development of $\sim 120 \%$. All mature males and females had food along the full length of the gut.

This vent margin site was barely active (temperature not recorded), supporting a few mussels and serpulid polychaetes.

\section{DISCUSSION}

\section{Reproductive ecology of Ventiella sulfuris}

Vent-endemic amphipods must adapt to conditions that are markedly different to the surrounding deep benthos. Temperatures are higher and food resources are generally greater. $V$. sulfuris at all vent sites stud- 
ied produced oocytes at numbers and of a maximum size comparable to those of shallow-water benthic amphipods; deep-sea, non-vent species generally produce much smaller broods of larger eggs (Johnson et al. 2001), though deep-sea scavenging species may produce large numbers (Ingram \& Hessler 1987). Although these reproductive changes at vents may be seen as adaptive responses to increased food resources and higher temperatures, they also serve to increase the number of offspring available for dispersal to new vents, an essential adaptation to population maintenance in this dynamic and often short-lived vent environment.

All of the vent sites studied, with the exception of Animal Farm (SEPR), supported populations that included juvenile to late immature stages. In all mussel bed populations, the smallest juveniles, mature males and mature females were absent. Populations supporting a wide range of growth stages such as these are typical of continuously reproducing species. Such populations are characteristic of environments with a continuous food supply, such as most temperate to tropical shallow-water environments (Sheader 1983, Johnson et al. 2001) and active hydrothermal vents (Sheader et al. 2000, 2004). At each site, males and females of Ventiella sulfuris approached maturity over a series of growth stages, though the exact stage at which they initiated and completed the process varied between individuals at a site, and the overall developmental maturation profile differed significantly between vent sites (Fig. 3). At the female growth stage prior to maturity, the oocytes grew rapidly, completely filling the peraeon, pushing into the head cavity, extending along the first pleon segment, and compressing the gut, thus preventing feeding. Late-stage immature males continued to feed. This degree of development of the ovaries is extreme, certainly in comparison to other vent species (Sheader et al. 2000, 2004) and many shallow-water species (Johnson et al. 2001) studied, though it is typical of deep-sea scavenging species (Hessler et al. 1978, Ingram \& Hessler 1987). In the later stages of oocyte development, the digestive diverticula became compressed, with no indication of accumulation of extensive reserves (limited lipid storage as indicated by Sudan Black staining).

Mature males and females and early juvenile stages were absent from mussel beds; this was also the case for the other vent habitat collections (tube worm beds, stauromedusae beds) examined, which otherwise supported a full range of growth stages. Despite large numbers of Ventiella sulfuris being collected in most EPR studies, no mature specimens have ever been recorded at vent sites. As a consequence, despite having large quantities of material, Barnard \& Ingram (1990) selected immature type specimens to represent the species. In our study, mature males and females were only recorded at the periphery of a vent. These consisted of early and late stage egg-bearing females, a post-brooding mature female, mature males together with a single late immature (OS5) female, with no other stages present. As no mature individuals have been found in central vent habitats, we conclude that, as maturity approaches, males and females move to the vent periphery where they moult to maturity, pair and produce eggs. They remain at or beyond the vent periphery as eggs develop and hatch and as the juveniles are released (indicated by the presence of a postbrooding female). The guts of all individuals in peripheral samples were full, indicating that females resume feeding after the eggs have been laid. There may be advantages in brooding at or beyond the vent periphery. Predation pressure on the adults and small juveniles (mainly from zoarcid fish) may be lower (Mullineaux et al. 2003). Lower temperature may be energetically beneficial for egg/juvenile development and adult survival in a food-poor environment. Also, there may be benefits in removing eggs and early juveniles from direct influence of the toxic materials associated with vent fluids. After 1 or (typically) 2 marsupial juvenile stages, early juveniles would be released to return to the home vent or colonise another vent.

The majority of amphipod species studied are iteroparous, producing a succession of broods once mature (Johnson et al. 2001). Records of semelparous amphipod species are much less frequent in the literature. They are mainly associated with habitats that have a marked seasonality of food supply (Leonardsson et al. 1988, Klages 1993, Ishikawa et al. 2004), with some species showing a change from iteroparity to semelparity with increase in latitude (Dias \& Sprung 2004). The well-developed ovary of Ventiella sulfuris, which completely fills all available space in the peraeon and extends into the head and pleon, is suggestive of semelparity, but there are a number of strong indications of iteroparity in this species. Firstly, mature $V$. sulfuris remain close to the vent margin and, subsequent to egg production and brooding, would have ready access to food at central vent habitats; iteroparity should be the most likely scenario with a continuous food resource available. Secondly, there is evidence from the pattern of oostegite development with growth stage (Fig. 3). OS5 females (the stage just prior to maturity) continued to be recorded in samples up to G14-G18 (5.4 to $6.4 \mathrm{~mm}$ body length), though the highest growth stage achieved was site dependent. With no OS4 females present in populations at a high enough growth stage to supply these OS5 females, the source of these is open to conjecture. Might OS5 females continue to moult whilst 
remaining at this oostegite stage? The great majority of OS5 females, irrespective of growth stage, were carrying well-developed vitellogenic oocytes, and all had developing setae under the marginal exoskeleton of the oostegites; they were ready to produce eggs within a fully developed marsupium at the next moult. Thus, the idea that OS5 females can pass through a series of moults and remain at this stage can be dismissed. The most likely interpretation is that OS5 females move to the vent periphery to moult to OS6 (i.e. mature) and produce a brood. At the next moult, OS6 females moult back to OS5 and return to the vents to feed and develop their next cohort of oocytes. This mode of reproduction, with a resting ('Ruhezeit') or preparatory stage between broods has been documented for a number of shallow-water (Sheader 1983, Johnson et al. 2000), deep-sea (Ingram \& Hessler 1987) and polar (Bone 1972) amphipods. The third line of evidence supporting iteroparity (with an intermediate 'Ruhezeit') comes from the analysis of oocyte size in relation to oostegite stage (Fig. 4). Note that oocytes in a given female develop synchronously, with very little variation in size within the oocyte cohort. Of interest here is that a proportion of OS5 females at each vent site contain a cohort of small oocytes $(<90 \mu \mathrm{m})$, with no other large oocytes present. This size class of females carrying small oocytes is absent at OS4. We would interpret those carrying cohorts of small oocytes at OS5 as 'Ruhezeit' females; OS5 oocyte data presented in Fig. 4 would, therefore, include females maturing for the first time after passing through OS1 to OS5 and with oocytes greater than $100 \mu \mathrm{m}$, together with 'Ruhezeit' females, a proportion of which would contain early oocytes $(<90 \mu \mathrm{m})$. The fourth line of evidence supporting iteroparity comes from the few mature females that were found in the peripheral vent sample. These each contained a cohort of early stage oocytes, indicating that multiple broods (iteroparity) are possible. Klages' (1993) study of the semelparous Antarctic amphipod Eusirus perdentatus found that none of the brooding females developed a further cohort of oocytes; Ventiella sulfuris clearly does.

\section{Number of broods and reproductive output}

With reference to the size distribution of OS5 females (Fig. 3) and assuming a moult back from OS6 to OS5 ('Ruhezeit') between broods, an estimate of the maximum number of broods produced by females at each site can be made.

For example, at Biovent, OS4 females can moult to give rise to OS5 females at G12, G13 and G14; the maximum number of broods would be dependent on the growth stage at which OS5 is achieved. This simple model at Biovent would give:

$$
\begin{gathered}
\text { OS5 (G12) } \rightarrow \text { OS6 (G13) Brood } \mathbf{1} \rightarrow \text { OS5 }(\mathrm{G} 14) \mathbf{R} \rightarrow \\
\text { OS6 (G15) Brood } \mathbf{2} \rightarrow \text { OS5 }(\mathrm{G} 16) \mathbf{R} \rightarrow \\
\text { OS6 (G17) Brood } 3
\end{gathered}
$$

and

$$
\begin{gathered}
\text { OS5 (G13) } \rightarrow \text { OOS6 (G14) Brood } 1 \rightarrow \text { OS5 (G15)R } \\
\rightarrow \text { OS6 (G16) Brood } 2 \rightarrow \text { OS5 (G17)R } \rightarrow \\
\text { OS6 (G18) Brood } 3
\end{gathered}
$$

and

$$
\begin{aligned}
& \text { OS5 (G14) } \rightarrow \text { OS6 (G15) Brood } 1 \rightarrow \\
& \text { OS5 (G16)R } \rightarrow \text { OS6 (G17) Brood } 2
\end{aligned}
$$

where $\mathbf{R}$ is 'Ruhezeit'.

Therefore, at Biovent, the maximum number of broods produced by females (either originating from females achieving OS5 at G12, G13, or G14) would be 2 or 3.

Since the maximum number of broods is dependent on the stage at which maturity is first achieved and the subsequent pattern of female mortality, it will differ both between cohorts within a site as well as between sites. The lowest number of broods is found at Rehu Marka (1 to 2 broods maximum), an intermediate number of broods at Train Station (2 to 3 broods maximum) and Biovent (2 to 3 broods maximum), with the highest number at East Wall (3 broods maximum) and Oasis (3 broods maximum).

Linking site-specific brood-size data (Fig. 6) with number of broods achieved per site allows an estimate of maximum reproductive output per female to be made. The total egg output is dependent on the growth stage at which females achieve OS5, and, hence, 2 to 3 values are given per site (Table 3 ).

Mean maximum egg output per female, weighted by the relative abundance of females at each growth stage, gives values of 108.5 at Biovent, 136.4 at East Wall, 104.7 at Train Station, 148.1 at Oasis and 53.2 at Rehu Marka. Although reproductive output was ventsite dependent, there was no apparent relationship to vent age (Spearman's rank correlation, $\mathrm{r}_{\mathrm{s}}=0.5$, not significant).

Although the evidence strongly indicates iteroparity, if Ventiella sulfuris were semelparous, then mean brood size and reproductive output would be much lower (39.3 at Biovent, 45.0 at Oasis, 44.6 at East Wall, 35.1 at Train Station and 31.2 at Rehu Marka). This maximum egg output is higher than recorded for other vent amphipod species (mid-Atlantic Ridge, Bouvierella curtirama, 38 to 57 eggs female ${ }^{-1}$ - Sheader et al. 2004; NEPR, Halice hesmonectes, 26+ eggs female $^{-1}$-Sheader et al. 2000), but it is still low compared to the majority of vent invertebrates with pelagic 
Table 3. Ventiella sulfuris. Estimated maximum reproductive output per female at vent sites. At each site, females attain Oostegite Stage 5 (OS5) at different growth stages (G11 to G14). The egg output is dependent on the stage at which females mature

\begin{tabular}{|lcccc|}
\hline Location & $\begin{array}{c}\text { Growth stage } \\
\text { when OS5 } \\
\text { is reached }\end{array}$ & $\begin{array}{c}\text { Max. no. } \\
\text { of broods } \\
\text { female }^{-1}\end{array}$ & $\begin{array}{c}\text { Max. egg } \\
\text { output } \\
\text { female }^{-1}\end{array}$ & $\begin{array}{c}\text { Mean max. } \\
\text { egg output } \\
\text { female }^{-1}\end{array}$ \\
\hline Biovent & G12 & 3 & 126.7 & 108.5 \\
East Wall & G13 & 3 & 128.8 & \\
Train Station & G14 & 2 & 86.7 & \\
& G13 & 3 & 133.2 & 136.4 \\
Oasis & G12 & 3 & 138.8 & \\
Rehu Marka & G13 & 3 & 109.1 & 104.7 \\
& G13 & 2 & 124.9 & \\
& G14 & 3 & 76.5 & \\
& G12 & 3 & 145.6 & 148.1 \\
\hline
\end{tabular}

larvae. Low reproductive output together with the absence of a larval stage would act to limit dispersal, supporting the 'Stepping Stone' model suggested for this species (France et al. 1992).

Egg size (early eggs $\sim 516 \mu \mathrm{m}$ diameter) is moderately large, and the equation relating egg diameter and juvenile size at hatching (Steele \& Steele $1991-$ incorporating results from several species) gives a first instar body length of $1.6 \mathrm{~mm}$. This exceeds the mean length for the earliest instar (G6 at $1.4 \mathrm{~mm}$ ) recorded from the mussel beds. This difference between predicted and observed values is within the lower limit of the between-species variation for amphipod eggs of this size (Steele \& Steele 1991). We conclude that the earliest post-marsupial juveniles recruit directly to central vent habitats.

\section{Impact of vent age on population structure and reproductive ecology}

Vents are dynamic and often relatively short-lived features. At EPR sites, the fauna display a characteristic pattern of zonation along the vent flux gradient (Hessler et al. 1985), with mussels occupying areas with temperatures up to $10^{\circ} \mathrm{C}$ above ambient. The gradient in fluid flux also represents a productivity gradient, reflected in faunal density and cover (Mullineaux et al. 2003). Ventiella sulfuris is motile and able to occupy a range of vent habitats, but is especially abundant in and around mussel and tube-worm beds. Even within vent habitats, at very small spatial scales, vent flux can be variable (Mullineaux et al. 2003). When vents are formed, fluid flux and temperatures are often initially high, declining with time, though the pattern of change at individual vents differs. Since the main energy resource at vents is derived from the venting process, a decrease in flux would be expected to reduce the overall food resource available. V. sulfuris is considered a bacterial detritus feeder (Vinogradov 1993). At EPR vents, the abundance of $V$. sulfuris declined with vent age (Fig. 1), though this was not reflected in changes in reproductive and other population parameters, which were found to be vent-site specific. If populations of $V$. sulfuris were food limited at vents of all ages, then with decline in the food resource, it would be expected that population density would fall, as found in this study.

The process of vent colonisation was relatively rapid, and, within $4 \mathrm{yr}$ of vent formation, breeding populations of Ventiella sulfuris were fully established (East Wall, NEPR). At the oldest vent sampled, Animal Farm (SEPR), although a mussel bed survived, temperature was just above ambient, with the rate of venting low; under these conditions the vent was unable to support a population of $V$. sulfuris. The amphipod occurred at vents at a range of ages, and the species seems capable of thriving throughout much of the active venting period and under variable vent flux conditions.

\section{Impact of spatial scale on population structure and reproductive ecology}

The current study is limited to mussel bed populations of Ventiella sulfuris, although this highly motile species can be abundant at a range of habitats at each vent site. Van Dover (2002) suggested that $V$. sulfuris was unlikely to show long-term fidelity to a given patch of mussels, with population changes on the scale of hours. The results from samples appear to support this concept of high within-site motility, with populations exhibiting low within-site variation in population structure and reproductive output. Motility acts to reduce the impact on populations resulting from temporal and spatial variation in environmental conditions and resources. East Wall had the greatest withinsample variation in population structure; this site is close to 2 other vents (Mussel Bed at $105 \mathrm{~m}$ to the north and Tica at $298 \mathrm{~m}$ to the south), and exchange between these 3 neighbouring sites may account for the increased heterogeneity in population structure recorded at East Wall.

Between most sites and between vent fields, significant differences in population structure and reproductive output were recorded. Although the NEPR sites 
Biovent and East Wall, separated by only $800 \mathrm{~m}$, were not significantly different in population structure, they differed in reproductive parameters, including female size and reproductive output. Two sites separated by $29^{\circ}$ of latitude, Biovent (NEPR) and Oasis (SEPR), supported population structure that did not differ significantly, but, again, reproductive parameters did differ significantly.

Within our study, there were significant differences in the population structure and reproductive output down to our minimum vent-site separation of $800 \mathrm{~m}$, implying high site fidelity and relatively little movement between adjacent vents at this spatial scale. The partitioning of phases of the life cycle between growth in the productive central vent area and reproduction at the vent periphery, with subsequent return to the vent for feeding and gonad development, is an adaptation that would support relatively high vent fidelity. However, if populations are to persist, migration between the short-lived vent environments must occur regularly. On a larger spatial scale, between vent sites, genetic-structure analysis of Ventiella sulfuris indicates that the species migrates along the ridge axis in a stepping-stone manner, unconstrained by distances as great as $1200 \mathrm{~km}$ (migration rate $M$ ranged from 1.9 to 67.8 ind. generation ${ }^{-1}$, dependent on site separation) (France et al. 1992). Note that these migration rates indicate historical patterns of gene flow and do not necessarily represent a continuous exchange among sites.

If exchange between adjacent vents were high, then it would be expected that vents within a field would have similar population structure and reproductive parameters, but this is not the case. The SEPR sites Oasis and Rehu Marka, separated by only $850 \mathrm{~m}$, show perhaps the greatest differences between adjacent sites. However, similar between-site differences could remain, even at high levels of population exchange, providing the exchange was limited to small juveniles; these would then develop according to prevailing environmental conditions at the site and their response would be indistinguishable from individuals produced on site. However, exchange of later stages would serve to reduce between-site variation, and as the results indicate significant site-specific differences, betweensite movement of later stages is likely to be minimal. Small juvenile stages are therefore likely to be the primary colonisers. This is also true of the EPR vent-endemic amphipod Halice hesmonectes; vents in the early stages of colonisation are dominated by early juvenile stages of $H$. hesmonectes (Sheader et al. 2000).

Ventiella sulfuris population structure and reproductive parameters are vent-site specific and appear unrelated to latitude (vent field), to vent age, or to population responses at adjacent vents. Populations respond and adapt to the conditions prevailing at each vent. In this respect, $V$. sulfuris behaves in much the same way as certain shallow-water species that are able to respond to environmental change by adjusting their population structure and reproductive output (Sheader 1983, Maltby \& Naylor 1990, Ford et al. 2003). In shallow-water species, this has led to their use as non-specific biomarkers of environment condition or change, and there is clearly potential for their use at vents as biomarkers of vent 'condition'. Such a biomarker would integrate (by their high within-site motility) over the range of habitats utilised by the species at each vent, but also integrate the impact of conditions over short time periods (over a generation timescale, ca. months to years - in the present study, populations were fully established at sites within $4 \mathrm{yr}$ of formation, indicating a generation time within this period). If such biomarkers are to be of value, then the way in which they vary in response to changes in vent parameters (e.g. community parameters, temperature, $\mathrm{pH}$, oxygen, metals, sulphide concentration, food quality) would need further investigation.

All 3 vent-endemic amphipods studied to date differ in their adaptations to the vent environment. Bouvierella curtirama on the slow-spreading mid-Atlantic Ridge is found at relatively long-lived vent sites, with topography acting to restrict the movement of populations along the ridge axis (Sheader et al. 2004). In this species, populations are resident at vents (all stages present), passing through successive generations, with adjacent vents showing differences in population structure and reproductive output. Results indicate that individuals exhibit relatively high vent fidelity. Both Halice hesmonectes and Ventiella sulfuris occur at relatively short-lived vents on the fast-spreading EPR. H. hesmonectes colonises vents within a few months of their formation (Sheader et al. 2000). Females and males leave the vent at the instar prior to maturity, each female containing a cohort of large oocytes and with the digestive diverticula grossly distended with reserves (Sudan Black staining indicates a high quantity of lipid); these reserves would be available to fuel further broods or transport adults between vents. Mature adults do not return to vents, and colonisation is by small juveniles. For this species, population structure and reproductive output are similar at different vents, suggesting that vent fidelity is relatively low. $V$. sulfuris largely replaces $H$. hesmonectes at EPR sites over time. $V$. sulfuris remains an abundant component of the vent fauna over much of the period of active venting at a site. The life-style characteristics of this species sit between those of $B$. curtirama and $H$. hesmonectes, with the species exhibiting moderate vent fidelity and higher reproductive output, and adults returning to vents to feed between broods. 
Acknowledgements. Field collections were supported by grants from the National Science Foundation to C.L.V.D. (OCE0350554, OCE9818550, OCE9982999) and to Janet Voight (DFB-0072695). We are grateful to the captain and crew of R/V 'Atlantis', the pilots and technicians of 'Alvin' and the shipboard scientific parties for assistance in sample collection. Thanks to Kate Davies for preparation of figures.

\section{LITERATURE CITED}

Barnard JL, Ingram C (1990) Lysianassoid amphipod (Crustacea) from deep-sea hydrothermal vents. Smithson Contrib Zool 499:1-80

Bat L, Raffaelli D (1998) Sediment toxicity testing: a bioassay approach using the amphipod Corophium volutator and the polychaete Arenicola marina. J Exp Mar Biol Ecol 226: 217-239

Bone DG (1972) Aspects of the biology of the Antarctic amphipod Bovallia gigantea Pfeffer at Signy Island, South Orkney Islands. Br Antarc Surv Bull 27:105-122

Clarke KR, Gorley RN (2001) PRIMER v5. PRIMER-E Ltd., Plymouth

Dias N, Sprung M (2004) Population dynamics and production of the amphipod Orchestia gammarellus (Talitridae) in a Ria Formosa saltmarsh (southern Portugal). Crustaceana 76(9):1123-1141

Ford AT, Fernandes TF, Rider SA, Read PA, Robinson CD, Davies IM (2003) Measuring sublethal impacts of pollution on reproductive output of marine Crustacea. Mar Ecol Prog Ser 265:303-309

France SC, Hessler RR, Vrijenhoek RC (1992) Genetic differentiation between spatially-disjunct populations of the deep-sea hydrothermal vent-endemic amphipod Ventiella sulfuris. Mar Biol 114:551-559

Haymon RM, Fornari DJ, Von Damm KL, Lilly MD and 11 others (1993) Volcanic eruption of the mid-ocean ridge along the East Pacific Rise crest at $9^{\circ} 45-52^{\prime} \mathrm{N}$ : direct submersible observations of seafloor phenomena associated with an eruption event in April, 1991. Earth Planet Sci Lett 119:85-101

Hessler RR, Ingram CL, Yayanos AA, Burnett BR (1978) Scavenging amphipods from the floor of the Philippine Trench. Deep-Sea Res 25:1029-1047

Hessler RR, Smithey WM, Keller CH (1985) Spatial and temporal variation of giant clams, tubeworms and mussels at deepsea hydrothermal vents. Bull Biol Soc Wash 6:465-474

Ikeda T (1990) A growth model for a hyperiid amphipod Themisto japonica (Bovallius) in the Japan Sea, based on its intermoult period and moult increment. J Oceanogr Jpn 46:261-272

Ingram CL, Hessler RR (1987) Population biology of the deepsea amphipod Eurythenes gryllus: inferences from instar analysis. Deep-Sea Res 34:1889-1910

Ishikawa T, Narita T, Urabe J (2004) Long-term changes in the abundance of Jesogammarus annandalei (Tattersall) in Lake Biwa. Limnol Oceanogr 49(5):1840-1847

Johnson WS, Stevens S, Watling L (2001) Reproduction and development of marine peracaridans. Adv Mar Biol 39:105-260

Editorial responsibility: Lisa Levin (Contributing Editor), La Jolla, California, USA
Klages M (1993) Distribution, reproduction and population dynamics of the Antarctic gammaridean amphipod Eusirus perdentatus Chevreux, 1912 (Crustacea). Antarct Sci 5(4):349-359

Leonardsson K, Sörlin T, Samberg H (1988) Does Pontoporeia affinis (Amphipoda) optimize age at reproduction in the Gulf of Bothnia? Oikos 52:328-336

Maltby L, Naylor C (1990) Preliminary observations on the ecological relevance of the Gammarus 'scope for growth' assay: effect of zinc on reproduction. Funct Ecol 4: 393-397

Mullineaux SL, Peterson CH, Michell F, Mills SW (2003) Successional mechanism varies along a gradient in hydrothermal fluid flux at deep-sea vents. Ecol Monogr 73(4): $523-542$

Roddie BT, Thain JE (2002) Biological effects of contaminants: Corophium sp. sediment bioassay and toxicity test. ICES Tech Mar Environ Sci 28, 20 pp

Shank TM, Fornari DJ, Von Damm KL, Lilley MD, Haymon RM, Lutz RA (1998) Temporal and spatial patterns of biological community development at nascent deep-sea hydrothermal vents $\left(9^{\circ} \mathrm{N}\right.$, East Pacific Rise). Deep-Sea Res Part II 45:465-516

Sheader M (1981) Development and growth in laboratorymaintained and field populations of Parathemisto gaudichaudi (Hyperiidea: Amphipoda). J Mar Biol Assoc UK 61:769-787

Sheader M (1983) The reproductive biology and ecology of Gammarus duebeni (Crustacea: Amphipoda) in southern England. J Mar Biol Assoc UK 63:517-540

Sheader M, Van Dover CL, Shank TM (2000) Structure and function of Halice hesmonectes (Amphipoda: Pardaliscidae) swarms from hydrothermal vents in the eastern Pacific. Mar Biol 136:901-911

Sheader M, Van Dover CL, Thurston MH (2004) Reproductive ecology of Bouvierella curtirama (Amphipoda: Eusiridae) from chemically distinct vents in the Lucky Strike vent field, Mid-Atlantic Ridge. Mar Biol 144:503-514

Steele DH, Steele VJ (1991) Morphological and environmental restraints on egg production in amphipods. In: Wenner A, Kuris A (eds) Crustacean egg production. AA Balkema, Rotterdam, p 157-170

Van Dover CL (2000) The ecology of deep-sea hydrothermal vents. Princetown University Press

Van Dover CL (2002) Community structure of mussel beds at deep-sea hydrothermal vents. Mar Ecol Prog Ser 230: 137-158

Van Dover CL (2003) Variation in community structure within hydrothermal vent mussel beds of the East Pacific Rise. Mar Ecol Prog Ser 253:55-66

Vinogradov GM (1993) Amphipods from hydrothermal vents of the eastern Pacific (in Russian). Zool Zh 72:40-53

Wiklund AE, Sundelin B (2004) Biomarker sensitivity to temperature and hypoxia - a seven year field study. Mar Ecol Prog Ser 274:209-214

Yamada Y, Ikeda T, Tsuda A (2004) Comparative life-history study of sympatric hyperiid amphipods (Themisto pacifica and T. japonica) in the Oyashio region, western North Pacific. Mar Biol 145(3):515-527

Submitted: July 29, 2005; Accepted: May 22, 2006

Proofs received from author(s): January 23, 2007 